\section{Consumer Preferences for Potted Orchids in the Hawaiian Market}

\author{
Marco A. Palma ${ }^{1,5}$, Yu-Jen Chen ${ }^{2}$, Charles Hall ${ }^{3}$, David Bessler ${ }^{4}$, \\ and David Leatham ${ }^{4}$
}

AdDitional INDEX wORDs. choice experiments, conjoint analysis, flowers, ornamentals, Orchidaceae

Summary. The wholesale value of potted orchids (Orchidaceae) in the United States has risen $80 \%$ in the last decade to $\$ 126$ million in 2007 . However, market-related information concerning consumer demand is still very limited. The objective of this study was to identify consumer preferences affecting orchid purchases and the relative importance of different orchid attributes, including species, price, size, and color. A survey to assess orchid market preferences was conducted in Akatsuka Orchid Gardens, headquartered on the Island of Hawaii during the Spring 2008. A conjoint analysis was developed to analyze consumer preferences for orchid attributes. Hawaii is the third largest orchid-consuming state in terms of sales, with $\$ 16.8$ million in 2007 . Most respondents $(\mathbf{5 7 . 8 \% )}$ were able to identify the specific orchid species they bought, but a large portion (42.2\%) was not able to identify any orchid species. The conjoint analysis results revealed that price was the most important factor affecting the purchasing decision, representing $30.90 \%$ of influence, followed by size $(26.28 \%)$ and species $(25.58 \%)$, while color $(17.23 \%)$ was the least important orchid attribute.

$\mathrm{O}$ rchids are the fastest-growing group of potted flowering plants in the United States in terms of sales, ranked second behind poinsettia (Euphorbia pulcherrima) among all potted flowering plants. Southern and western states are the main producing regions in the United States, accounting for more than $91 \%$ of the wholesale value of orchid production in 2007. According to the U.S. Department of Agriculture (USDA), over the past 10 years, the number of potted orchid production increased $61 \%$ from 9.58 million units in 1997 to 15.4 million units in 2007, while the wholesale value of orchids increased $80 \%$ from $\$ 70$ million in 1997 to $\$ 126$ million in 2007, as shown in Fig. 1. Sales of orchids peaked in 2005 at $\$ 139$ million and then dropped to $\$ 126$ million in 2007. Declining sales were due in part to a $70 \%$ increase in foreign

${ }^{1}$ Department of Agricultural Economics, Texas A\&M University, 2124 TAMU, College Station, TX 778432124

${ }^{2}$ Research Assistant, Department of Agricultural Economics, Texas A\&M University, 2124 TAMU, College Station, TX 77843-2124

${ }^{3}$ Professor, Department of Horticultural Sciences and Holder of the Ellison Chair in International Floricul ture. 2133 TAMU, College Station, TX 77843-2133

${ }^{4}$ Professor, Department of Agricultural Economics, 2124 TAMU, College Station, TX 77843-2124

${ }^{5}$ Corresponding author. E-mail: mapalma@tamu.edu. imports of live orchids since 2005 (USDA, 2007).

Overall demand for orchids has also declined with higher energy and food prices in 2006 (USDA, 2007). Orchid sales per capita declined from $\$ 0.47$ in 2005 to $\$ 0.42$ in 2007 , while the domestically produced orchid price index increased from 81.4 in 2004 to 89.0 in 2007 (base price of 100 was in year 2000). In the past 10 years, the value of potted orchid imports has risen almost five times, and is projected to continue to grow in the near future. Today, Taiwan is the major orchid supplier to the United States $(55 \%)$, and has increased their import value $32 \%$ from 2005 to $\$ 18$ million in 2006 . This increase is driven by the trade liberalization of the orchid markets with Taiwan, particularly the specifications regarding approved media (USDA, 2006). Other important exporters to the United States include Thailand, the Netherlands, and Canada, with a combined value of $\$ 10.3$ million (31\%) in 2006 (USDA, 2007).

Overall orchid prices exhibited an increasing trend since 1997. The average price of orchids peaked at $\$ 9.18$ in 2000 , and then declined to $\$ 7.47$ in 2004. Meanwhile, the number of orchid producers has declined since 2002 from 261 to 177 in 2007 , but the average sales per producer has increased as shown in Fig. 2. In the long term, prices are expected to stabilize or maybe even decline as a result of increased low-priced foreign supplier competition and larger U.S. growers selling more products to mass merchandising markets (USDA, 2007).

California, Florida, and Hawaii are the major potted orchid producing states in the United States, accounting for $94 \%$ of total orchid production. In 2007 , California produced about $42 \%$ of the U.S. production, with 6.5 million pots, followed by Florida (34\%) and Hawaii (18\%), with 5.3 million and 2.8 million pots, respectively. Wholesale production values in 2007 were estimated at $\$ 56.5$ million for California, \$41.9 million for Florida, and \$16.8 million for Hawaii (USDA, 2007).

The prevailing potted orchid colors produced were single color white, red, and yellow. Other colors and color pattern combinations are available as a result of breeding. Even though statistics of production, sales, and prices for all orchid species are not available on a yearly basis, there is some limited market information available regarding the predominant potted orchid species. Moth orchid (Phalaenopsis spp.) dominates the U.S. orchid market, and accounts for more than $80 \%$ of all orchid production value (Griesbach, 2002; Runkle et al., 2005).

The location of Hawaii provides ideal conditions and the perfect natural environment for orchids to grow year round. However, its potted orchid production has remained relatively flat since 2002, due to increasing competition from foreign suppliers and larger domestic producers. Island of Hawaii accounted for $65 \%$ of the state's total wholesale value for all orchids (including cut orchids), with

\begin{tabular}{llll}
\hline $\begin{array}{l}\text { Units } \\
\begin{array}{l}\text { To convert U.S. to SI, } \\
\text { multiply by }\end{array}\end{array}$ & U.S. unit & SI unit & $\begin{array}{l}\text { To convert SI to U.S., } \\
\text { multiply by }\end{array}$ \\
\hline 2.54 & inch(es) & $\mathrm{cm}$ & 0.3937
\end{tabular}




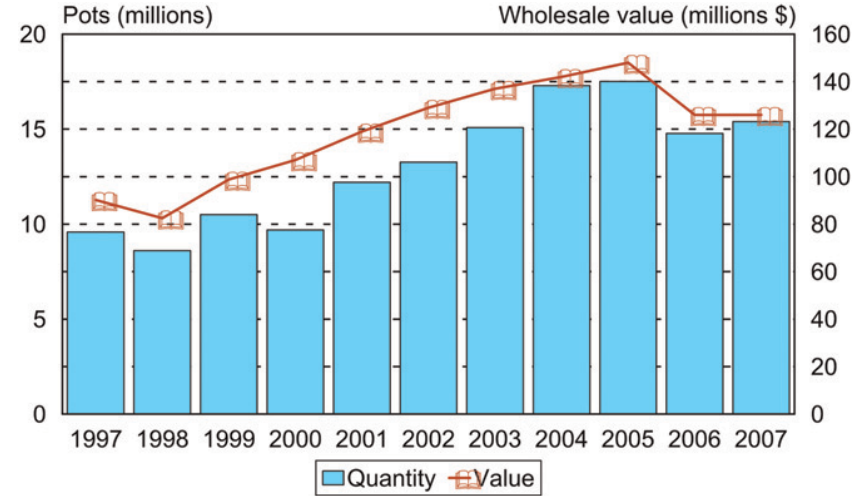

Fig. 1. Wholesale quantity and value of potted orchids in the United States from 1997 to 2007. Value was deflated to 2007 dollars (U.S. Department of Agriculture, 2007).

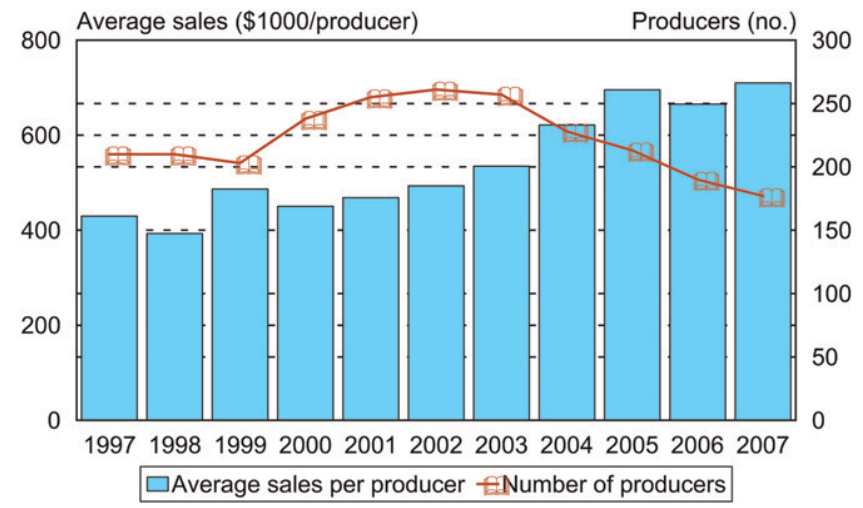

Fig. 2. Number and average sales of U.S. orchid producers from 1997 to 2007. Average sales were deflated to 2007 dollars (U.S. Department of Agriculture, 2007).

\$22.2 million in 2006 (Hawaii Department of Agriculture, 2007).

Unlike mainland markets where the predominant orchid is moth orchid, the Hawaiian potted orchid industry is dominated by "other potted orchids," including boat orchid (Cymbidium spp.), cattleya orchid (Cattleya spp.), lady slipper orchid (Paphiopedilum spp.), and pansy orchid (Miltonia spp.), followed by bamboo orchid (Dendrobium spp.), dancing ladies orchid (Oncidium spp.), and moth orchid. Before 2004 , dancing ladies orchid was the largest component in terms of sales for the "other" category of potted orchids and was subsequently separated from this category and reported independently. Dancing ladies orchid sales exceeded \$3.7 million in 2007. Hawaiian potted orchid prices have increased gradually in the past decade.

Even though orchids have experienced growth in the last decade, there is very little information concerning orchid markets and consumer preferences for orchid attributes. Several independent garden centers in Hawaii who are also orchid growers were interested in gaining insights into consumer attitudes and preferences for orchids and orchid attributes in the Hawaiian market. The main objective of this article was to analyze consumer preferences for orchids and orchid product attributes in the Hawaiian market. We used conjoint analysis to decompose consumer utility for orchids into its attributes and to weight the importance of each attribute in the purchasing decision. These results can then be used to assess the potential market acceptance of several different orchid products in the Hawaiian market.

\section{Materials and methods}

A survey to assess orchid market preferences in the Hawaiian market was conducted in Akatsuka Orchid Gardens, headquartered on Island of Hawaii during the Spring 2008. Respondents were randomly selected buyers at the various garden center locations and were asked to answer a written questionnaire regarding orchid preferences. A conjoint choice experiment was included in the survey to determine the importance of various orchid attributes and attribute levels that influence consumer purchasing decisions. Information regarding consumer purchasing habits was also collected in the market survey, which included the following categories of data: purchasing habits, purpose of the orchid purchase (self or gifts), purchasing frequency, total dollar amount spent, preferred outlet types, store features, orchid features, and color preferences. Demographic information was also collected, including gender, age, marital status, income, education level, and ethnicity.

Choice experiments such as conjoint analysis are a widely accepted technique used in marketing research that allow investigators to decompose the total utility obtained from consuming a product into the separate utility obtained by each key product attribute (Green and Srinivasan, 1978). The researcher can then measure the relative importance of each key attribute (Green and Wind, 1975; Louviere, 1988) and simulate market acceptance of different feasible products by combining different product features. This technique is also useful in marketing for designing new or potential products by using the results of consumer preferences and simulates their consumer acceptance in the marketplace (Wirth et al., 2007).

There are two basic steps to be considered when designing a conjoint analysis. The first step is to generate the relevant attributes and attribute levels for potted orchids. To accomplish this, focus groups interviews are typically used to identify the main product characteristics (attributes) and the corresponding meaningful levels for each attribute. The second step is to combine those attribute levels to form profile combinations that consumers will evaluate (Palma, 2002). Various attributes may affect consumer preferences for potted orchids, for example, plant color, condition, species, flower number 
and size, prices, and seasonal availability. Although price is not a product attribute, it plays an important role in consumer purchasing decisions, and is typically included in conjoint analysis to enable estimation of willingness to pay (Anderson, 1986). The levels for each attribute should then be assigned according to their practical relevance and should capture the feasible ranges of the attributes. Fewer numbers of attributes and attribute levels can increase the accuracy and predicting power of the model and can also decrease the size of the experiment (Louviere, 1988).

The product attributes and attribute levels were selected based upon interviews with several orchid growers and wholesalers in Hawaii. The design included three orchid attributes with three levels pot size [small (4 inches diameter), medium (5 inches diameter), and large (6 inches diameter $)]$, price per pot $(\$ 8$, $\$ 16$, and \$24), species (moth orchid, bamboo orchid, and others) and one with two levels: color (multicolor and single color) as shown in Table 1 . Thus, the experiment was a $3 \times 3 \times$ $3 \times 2$ factorial design yielding 54 different possible combinations of product features. In general, the size of the experiment increases as the number of attributes and attribute levels is increased. Obviously, it would be impractical to ask respondents to rate 54 or more product feature combinations. There are two ways to reduce the number of profiles.

Table 1. Selected orchid attributes and attribute levels used in the conjoint experiment of consumer preferences in a survey of orchid consumers in Hawaii in 2008.

\begin{tabular}{ll}
\hline Attribute & Attribute level \\
\hline Pot size & Small (4) \\
\multicolumn{1}{c}{ (inches diam) $)^{\mathrm{z}}$} & Medium $(5)$ \\
& Large $(6)$ \\
Price $(\$ /$ pot $)$ & 8.00 \\
& 16.00 \\
Color $^{\mathrm{y}}$ & 24.00 \\
& Single color \\
Species & Multicolor \\
& Moth orchid \\
& Bamboo orchid \\
& Other orchids \\
\hline
\end{tabular}

${ }^{\mathrm{z}} 1$ inch $=2.54 \mathrm{~cm}$.

y Single color is an orchid of one color and multicolor is a combination of more than one color.
The first approach would be to use a full design and to have different versions of the survey, each one with a certain number of profiles; for example, six survey versions with nine possible profiles each. The second approach would be to use a fractional factorial design in which feature levels are combined to yield a minimum amount of profiles while achieving independence among orchid features. Independence is commonly referred to as the orthogonality condition or orthogonal array (Green, 1974).

This research used a fractional factorial design (the orthogonal array) with SPSS (version 13.0; SPSS, Chicago) to generate the lowest number of combinations for an orthogonal design. Orthogonality ensures that the estimated coefficients for each attribute are independent. The experiment included a tenth hold-out product (medium size multicolor moth orchid at \$16) in the market survey to examine the efficiency of the model in predicting the utility for a product feature combination. The hold-out product was not used in the conjoint experiment. Instead, the predicted utility value for the holdout product from the model can be compared with the average rating response by actual survey respondents to assess the predictive power of the choice experiment (Herman, 1988). The product profiles used in this study are shown in Table 2.

Consumer preference can be represented as a function of orchid attributes, and using the attributes selected for the orchid choice experiment, the consumer preference model is expressed as:

$$
\begin{aligned}
\text { Rating }= & f(\text { Size, Price, } \\
& \text { Color, Species })
\end{aligned}
$$

where rating is the consumer preference rating for each hypothetical orchid product from 0 to 10 , where 0 is the least preferred and 10 is the most preferred, and the variables are defined in Table 1.

Price was represented with a vector model as a linear quantitative variable. The rest of the variables (size, color, and species) were qualitative features represented with a part-worth functional form because it provides flexibility in approximating the preference function.

Qualitative variables are treated as dummy variables. As an alternative to traditional dummy variable coding, this study used effects coding, also known as mean deviation coding (Gillespie et al., 1998). The intercept indicates the average preference rating, and dummy variable coefficients measure deviation from the average rating. The conjoint analysis experiment model can be expressed as:

$$
\begin{aligned}
\text { Rating }= & \beta_{0}+\beta_{1} \text { Size } M+\beta_{2} \text { SizeL } \\
& +\beta_{3} \text { Colormulti }+\beta_{4} \text { Spph } \\
& +\beta_{5} \text { Spden }+\beta_{6} \text { Price }+\mu_{i}
\end{aligned}
$$

where

\begin{tabular}{|c|c|c|c|c|}
\hline & $\begin{array}{c}\text { Pot size } \\
(\text { inches diam })^{z}\end{array}$ & $\begin{array}{c}\text { Price } \\
\text { (\$/pot) }\end{array}$ & Color ${ }^{\mathrm{y}}$ & Species \\
\hline 1. & Small (4) & 8.00 & Single color & Moth orchid \\
\hline 2. & Medium (5) & 16.00 & Single color & Moth orchid \\
\hline 3. & Large (6) & 24.00 & Multicolor & Moth orchid \\
\hline 4. & Medium (5) & 8.00 & Multicolor & Bamboo orchid \\
\hline 5. & Large (6) & 16.00 & Single color & Bamboo orchid \\
\hline 6. & Small (4) & 24.00 & Single color & Bamboo orchid \\
\hline 7. & Large (6) & 8.00 & Single color & Other orchids \\
\hline 8. & Small (4) & 16.00 & Multicolor & Other orchids \\
\hline 9. & Medium (5) & 24.00 & Single color & Other orchids \\
\hline $10 .^{x}$ & Medium (5) & 16.00 & Single color & Moth orchid \\
\hline
\end{tabular}

Table 2. Orchid product profile combinations rated by respondents in a conjoint experiment of data collected by a survey of orchid consumers in Hawaii in 2008 . Rating scale is from 0 to 10 , where 0 is a not desirable product feature combination and 10 is a highly desirable product feature combination. 


$$
\begin{aligned}
& \text { SizeM = dummy variable for medium } \\
& \text { pot size orchid } \\
& \text { SizeL = dummy variable for large pot } \\
& \text { size orchid } \\
& \text { Colormulti }=\text { dummy variable for } \\
& \text { multicolor orchid } \\
& \text { Spph }=\text { dummy variable for moth } \\
& \text { orchid } \\
& \text { Spden }=\text { dummy variable for } \\
& \text { bamboo orchid }
\end{aligned}
$$

The base level attributes were specified as

$$
\begin{aligned}
\begin{aligned}
& \text { SizeS }= \text { dummy variable for small } \\
& \text { pot size orchid }
\end{aligned} \\
\begin{aligned}
\text { Colorsin }= & \text { dummy variable for } \\
& \text { single-color orchid } \\
\text { Spother }= & \text { dummy variable for } \\
& \text { other orchid species }
\end{aligned}
\end{aligned}
$$

In the consumer preference model analysis, rating scales were designed to elicit information for each product feature combination. The scale interval was set between 0 and 10 . This scale was chosen because ordered categorical variables with 11 categories or more can be treated as continuous (Anderson and Phillips, 1981; Nunnally and Bernstein, 1994). The preference model was estimated in TSP (version 4.5; TSP International, Palo Alto, CA) using a two-limit tobit model for estimating part-worth values to avoid the biased parameter problem of ordinary linear squares (OLS). Using OLS would yield truncated residuals and asymptotically biased estimates, and therefore, a two-limit tobit model was constructed considering the double truncated nature of the dependent variable (Harrison et al., 2001; Long, 1997).

\section{Results}

General Survey Results. A total of 401 observations were collected and used for the conjoint analysis estimation. Among these respondents, the demographic statistics revealed that age ranged from 18 to 76 years, with a mean age of 33.3 years. The percentage of female respondents was $63.6 \%$. In terms of respondents fell in the category of $\$ 25,000$ or less. A total of $93.1 \%$ of respondents had received at least a high school education, and the ethnicity breakdown of survey participants included $61 \%$ Asian-Pacific is-

In the survey, respondents were first asked to specify their purchasing habits regarding cut flowers. Most respondents $(66.7 \%)$ bought cut flowers on a regular basis. The regular purchase of roses (Rosa spp.) comprised $46.9 \%$ of respondents, $37.5 \%$ purchased anthuriums (Anthurium spp.), and $34.4 \%$ purchased lilies ( $\mathrm{Lil}$ ium spp.). About $58.1 \%$ of the respondents bought cut flowers for self consumption, while the rest bought them as gifts.

Even though most respondents identified the orchid species they bought $(57.8 \%)$, a large number of respondents $(42.2 \%)$ were not familiar with, and therefore could not specify, the orchid species they bought. The main orchid species identified were bamboo orchid $(37.8 \%)$, boat orchid $(31.1 \%)$, moth orchid $(22.2 \%)$, cattleya orchid $(20.0 \%)$, lady slipper orchid $(20.0 \%)$, and dancing ladies orchid (15.6\%). Around $84.5 \%$ of respondents only bought orchids occasionally or rarely and the main purpose of the purchase (for $52.3 \%$ of respondents) were for gift occasions. Most respondents were willing to spend $\$ 0$ to $\$ 15(37.2 \%)$ or $\$ 16$ to $\$ 30$ (39.5\%), while only $11.7 \%$ of the respondents were willing to pay more than $\$ 46$ on potted orchids.

Respondents were also asked to select their preferred outlets for buying orchids and to specify the features that prompted them to purchase yearly household income, $55 \%$ of the lander and $31.7 \%$ white.

from those outlets. A large proportion of respondents preferred farmers' markets $(48.9 \%)$, followed by flower shops $(24.4 \%)$, and garden centers $(24.4 \%)$. Price was the most important feature when they chose the store, with a mean rating of 8.3 on a scale of 10 , followed by service and attitude (7.0), and product availability (6.5), while store size (2.9) was the least important store feature. As expected, farmers' markets were the most preferred site because they had become an important scenic venue offering various local foods, arts, clothing, and flower shops, all of which are important entertainment or experience components.

As for the features of orchids that influence consumer purchasing preferences, price and color were the most significant attributes, with a mean rating of 7.6, followed by lasting quality (6.5) and style (5.4), while pot size (3.2) was the least important attribute. The preferred orchid colors were also evaluated in the market survey, with the top three preferred colors being red (6.2), purple (5.9), and white $(5.71)$. Also, $66.7 \%$ of respondents preferred orchids as a single pot without any arrangements. A significant portion of the respondents (55\%) had yearly incomes of less than $\$ 25,000$, which may have influenced the high rating of price because lowerincome households are generally more price conscious.

Conjoint anAlysis Results. The parameter estimates of the conjoint analysis model are presented in Table 3. All variables were significant except for pot size, suggesting that this product feature does not statistically influence the consumer's utility for a product.

Table 3. Parameter estimate coefficients of the conjoint analysis results and their statistical significance analyzed from data collected in a survey of Hawaiian orchid consumers in 2008.

\begin{tabular}{lccc}
\hline Variable & Coefficient & SE & t value $^{\mathrm{z}}$ \\
\hline Intercept & 7.30 & 0.49 & $15.03^{* * *}$ \\
Medium pot $(5 \text { inches diam })^{\mathrm{y}}$ & 0.26 & 0.26 & 1.02 \\
Large pot $(6 \text { inches diam })^{\mathrm{y}}$ & 0.38 & 0.26 & 1.47 \\
Multicolor & 0.33 & 0.19 & $1.73^{*}$ \\
Moth orchid & -0.54 & 0.25 & $-2.11^{*}$ \\
Bamboo orchid & 0.45 & 0.26 & $1.75^{* *}$ \\
Price & -0.07 & 0.03 & $-2.68^{* *}$ \\
\hline
\end{tabular}

${ }^{2}$ Compared with the mean preference value in a two-tail $t$ test.

$* * * * * *$ Significant at $P \leq 0.05,0.01$, or 0.001 , respectively.

${ }^{y} 1$ inch $=2.54 \mathrm{~cm}$.

${ }^{\mathrm{x}}$ Multicolor is a combination of more than one color 
The parameter for moth orchid (spph) and price had negative signs, implying that these product features will decrease the utility value of consumers. The price coefficient of -0.07 means respondents will reduce the preference rating by 0.07 for every $\$ 1$ increase in price. The negative sign of price is in accordance with economic theory (Nicholson, 1998).

Table 4 provides the calculated utility values for each level of each variable. For dummy variables of size, color, and species, each level's utility value is represented by the estimated coefficient. Price is a linear quantitative variable, and therefore, to calculate price utility value for each level, each price level was multiplied by the estimated coefficient. Because marginal effects are evaluated at each observation and average over the sample, using marginal effects would lead to the same relative rankings (Gillespie et al., 1998).

Table 4. Attribute utility values and relative importance of orchid attributes calculated from a conjoint analysis model developed from a survey of Hawaiian orchid consumers in 2008.

\begin{tabular}{|c|c|c|}
\hline Factor & Utility $^{\mathrm{z}}$ & $\begin{array}{c}\text { Relative } \\
\text { importance } \\
(\%)^{\mathrm{y}}\end{array}$ \\
\hline Base level & 7.30 & \\
\hline $\begin{array}{l}\text { Pot size } \\
\qquad(\text { inches diam })^{x}\end{array}$ & & 26.28 \\
\hline Small (4) & -0.64 & \\
\hline Medium (5) & 0.26 & \\
\hline Large (6) & 0.38 & \\
\hline Color $^{\mathrm{w}}$ & & 17.23 \\
\hline Multicolor & 0.33 & \\
\hline Single color & -0.33 & \\
\hline Species & & 25.58 \\
\hline Moth orchid & -0.54 & \\
\hline Bamboo orchid & 0.45 & \\
\hline Other orchids & 0.09 & \\
\hline $\begin{array}{l}\text { Purchase price } \\
\text { (\$/pot) }\end{array}$ & & 30.90 \\
\hline 8.00 & -0.60 & \\
\hline 16.00 & -1.19 & \\
\hline 24.00 & -1.79 & \\
\hline
\end{tabular}

${ }^{\mathrm{z}}$ Utility preference is measured in a scale from 0 to 10 , where 0 is a not desirable product and 10 is a very desirable product. The base level is 7.30; the attribute levels represent deviations from the base level. A negative sign means that attribute level reduces utility, and a positive sign means that attribute level increases utility.

${ }^{y}$ Relative importance of each attribute to consumer preference out of $100 \%$.

${ }^{\mathrm{x}} 1$ inch $=2.54 \mathrm{~cm}$.

wSingle color is an orchid of one color and multicolor

is a combination of more than one color.
The relative importance for each attribute was also calculated from the estimated parameters as the ratio of the difference between the highest and lowest utility for each attribute (range) and the sum of all ranges for all attributes, expressed as percentages of overall utility values in Table 4. Price $(30.90 \%)$ was the most important attribute, followed by size (26.28\%), species $(25.58 \%)$, and color $(17.23 \%)$. As discussed before, the large number of respondents in the lower income category may have influenced the significance of price.

Summary AND DISCUSSION. The most preferred or first-choice product would be the attribute combination having the highest utility values, which is a large multicolor bamboo orchid at the lowest price of $\$ 8.00$. The base utility level of 7.30 represents the mean rating, and the attribute level utility values are deviations from the mean. For example, a smallsized pot would reduce the utility rating 0.64 , while medium and large sizes would increase utility ratings 0.26 and 0.38 , respectively. Similarly, multicolor was preferred over single color and would increase the utility rating 0.33 . The most preferred species was bamboo orchid, and it would increase the utility ratings 0.45 . Other species would increase utility ratings (0.09), but not as much as bamboo orchid, while moth orchid would reduce consumer's utility. As expected, there is an inverse relationship between price and utility preferences, as evidenced by the negative signs in the price coefficients. In general, the higher the price, the more it would reduce utility.

The results can be applied for other products of interest by combining attribute levels to form potential products and their potential acceptance can then be assessed by adding up the utility values of each attribute level to measure their market acceptance. But before doing that, one must consider the reliability of the experimental results and the ability of the model to accurately predict utility. This is accomplished by calculating the utility of the hold-out product predicted by the model and comparing that utility with the actual customer's average response in the survey. Our orchid conjoint experiment model predicted a utility value for the holdout product of 6.16 compared with the hold-out product's actual average preference rating of 6.93 , with a standard deviation of 3.03 , suggesting that the model has good predictive power (less than one-quarter of a standard deviation difference).

Results of this study suggest that price is the primary factor that influences consumer preference for purchasing orchids, followed very closely by size and species. A significant portion of respondents $(55.0 \%)$ had a yearly income of less than $\$ 25,000$, which may explain the high significance of price, as lower income households are more price conscious. The results suggest that orchid growers in the state of Hawaii would benefit by growing larger orchid pots (5- and 6inch-diameter pots), with less expensive species that can be sold at a lower price. Even though specific colors were not used in the choice experiment design, consumers prefer a multicolor orchid. The preferred colors were recorded in the survey results section. This article based its results in a survey in Hawaii as it was of particular interest to a group of independent garden centers in Hawaii who also grow orchids. While these results cannot be extrapolated to represent preferences of the total population of orchid consumers in the United States, it provides insights for consumers on the Island of Hawaii, and may also be useful in designing an extension of this article to determine flowering plant buying preferences in other regions of the country.

\section{Literature cited}

Anderson, J.A. and P.R. Phillips. 1981. Regression, discrimination, and measurement models for ordered categorical variables. Appl. Stat. 30(1):2231.

Anderson, J.L. 1986. Conjoint analysis of the New England seafood market. Canadian Department of Fisheries and Oceans, Vancouver, BC, Canada.

Gillespie, J., G. Taylor, A. Schupp, and F. Wirth. 1998. Opinions of professional buyers towards a new, alternative red meat. Ostrich. Agribusiness Intl. J. 14(3): 247256.

Green, P.E. 1974. On the design of choice experiments involving multifactor alternatives. J. Consum. Res. 1(2):6168.

Green, P.E. and V. Srinivasan. 1978. Conjoint analysis in consumer research: Issues and outlook. J. Consum. Res. 5(2): 103123. 
Green, P.E. and Y. Wind. 1975. New ways to measure consumer's judgments. Harv. Bus. Rev. (July-August):89108.

Griesbach, R.J. 2002. Development of Phalaenopsis orchids for the mass-market, p. 458-465. In: J. Janick, and Whipkey A. (eds.). Trends in new crops and new uses.. Amer. Soc. Hort. Sci. Press, Alexandria, VA.

Harrison, R.W., J. Gillespie, and D. Fields. 2001. Theoretical and empirical considerations of eliciting preferences and model estimation in conjoint analysis. Amer. Agr. Econ. Assn. Annu. Mtg., Chicago.

Hawaii Department of Agriculture. 2007. Hawaii flowers and nursery products annual summary 2007. Hawaii Department of Agriculture, Honolulu.
Herman, S. 1988. Software for full profile conjoint analysis. Proc. Sawtooth Software Conf. 2: 117-130. 26 Aug. 2009. <http://www.skimgroup.com/technical_ papers/past_conference_proceedings/ 1988Proceedings.pdf>.

Long, J.S. 1997. Regression models for categorical and limited dependent variables. Sage Publications, Thousand Oaks, CA.

Louviere, J.J. 1988. Analyzing decision making: Metric conjoint analysis. Sage Publications, Newbury Park, CA.

Nicholson, W. 1998. Microeconomic theory, basic principles and extensions. Dryden Press, Fort Worth, TX.

Nunnally, J.C. and I.H. Bernstein. 1994. Psychometric theory, 3rd ed. McGraw Hill, New York.
Palma, M.A. 2002. Market preferences toward farm-raised sturgeon in the southeastern United States: A conjoint analysis. Univ. Florida, Gainesville, M.S. thesis.

Runkle, E., Y. Wang, M. Blanchard, and R. Lopez. 2005. The orchid grower. Greenhouse Grower 23(8):6467.

U.S. Department of Agriculture. 2006. Market update on Taiwan orchid exports to the U.S. Foreign Agr. Serv., U.S. Dept. Agr., Washington, DC.

U.S. Department of Agriculture. 2007. Floriculture and nursery crops yearbook. Econ. Res. Serv., U.S. Dept. Agr., Washington, DC.

Wirth, F.F., L.A. Love, and M.A. Palma. 2007. Purchasing shrimp for at-home consumption: The relative importance of credence versus physical product features. Aquaculture Econ. Mgt. 11(1):1737. 